\title{
A alimentação no contexto contemporâneo: consumo, ação política e sustentabilidade
}

\author{
Food in the contemporary context: \\ consumption, political action and sustainability
}

Fátima Portilho ${ }^{1}$

M arcelo Castañeda ${ }^{1}$

Inês Rugani Ribeiro de Castro ${ }^{2}$

\footnotetext{
1 Programa de

Pós-Graduação deCiências

Sociais em

Desenvolvimento,

Agricultura eSociedade,

Universidade Federal Rural

do Rio de aneiro. Av.

Presidente Vargas 417, 90

andar, Centro. 20071-003

Rio deJaneiro RJ.

faportilho@uol.com.br

${ }^{2}$ Instituto deNutrição,

Universidade do Estado do

Rio deJaneiro.
}

Abstract Theinterdisciplinary field of reflections on food as politics goes through a process of expansion and overflow to the private sphere, and routine daily food consumption. This process seems to bea reflection of transformationsin the global agrifood markets, the wide publicity and awareness of food hazards and the politicization of consumption. To the extent that individuals are to assume responsibility for the environmental and social consequences of their everyday choices, the specificity of political power in contemporary societies goes beyond the institutional level (food security and nutrition, social inequalities in access to food, agricultural policies and regulations advertising of food) to meet the private sphere. This paper shows, initially, some of the recent debates about the process of politicization of consumption and then explores a theoretical reflection on the ethical, political and ideological habits that relate to food consumption, induding thelocationsand ways of acquiring and food preparation, the values of environmental preservation, solidarity with local producers and reflexive caution against food risks. Finally, points to a research agenda capable of capturing the processes of politicization of food and consumer practices in the field of political power. Key words Food consumption, Political action, Sustentability, Risks, Politicization of consumption
Resumo 0 campo interdisciplinar de reflexões sobre a alimentação como campo político passa por um processo de expansão e transbordamento para a esfera privada, cotidiana e rotineira do consumo alimentar. Tal processo parece ser reflexo de transformações nos mercados agroalimentares globais, da ampla percepção e publi cização dos riscos alimentares e da politização do consumo. U ma vez que os indi víduos assumem responsabilidades sobre as consequências ambientais e sociais de suas escolhas cotidianas, a especificidade política da alimentação nas sociedades contemporâneas extrapola a esfera institucional (segurança alimentar e nutricional, desigualdades sociais no acesso à alimentação, políticas agrícolas e regulamentação da publicidade de alimentos) para atingir a esfera privada. 0 artigo aborda alguns dos recentes debates sobre o processo de politização do consumo e faz uma reflexão teórica sobre as dimensões ética, política e ideológica que relacionam hábitos de consumo alimentar, incluindo locais e formas de aquisição e preparo dos alimentos, valores de preservação ambiental, solidariedade com pequenos produtores locais e precaução reflexiva ante os riscosalimentares. A ponta ainda uma agenda de pesquisa capaz de captar processos de politização da comida e práticas de consumo político no campo da alimentação.

Palavras-chave Consumo alimentar, Ação política, Sustentabilidade, Riscos, Politização do consumo 
Introdução:

a alimentação como campo político

As reflexões sobre alimentação e nutrição como campo político costumam enfatizar um conjunto de questões tradicional mente relacionadas à arena do Estado, tais como segurança alimentar e nutricional, direitos humanos, desigual dades sociais no acesso à comida, políticas nutricionais e agrícolas, bem como a regulamentação da publicidadedealimentos. Ao considerar o sistema agroalimentar global, as análises se voltam mais para as regras do comércio internacional de commodities, a dominação das corporações multinacionais, a expansão do setor supermercadista, a desregulamentação e globalização dos mercados agroalimentares e a valorização de qualidades específicas edeorigem. Em uma arena micropolíti$\mathrm{ca}$, tais reflexões costumam enfocar aspectos como a organização social do trabalho e o papel dos gêneros na produção doméstica da comida ${ }^{1,2}$.

Tais reflexões utilizam tradicional menteuma abordagem estadocêntrica, considerando a comida como um conjunto de nutrientes e a política como aquilo que as instituições fazem ou deixam de fazer. No entanto, aspectos como a crise de legitimidade que caracteriza a vida política contemporânea e a desregulação e liberalização que passam a afetar a produção agroalimentar a partir da década de 1990 contribuem para tornar estreito o foco exclusivo em políticas institucionais, burocracias ou representantes políticos. Ao considerar que a política, assim como a comida, encontra-se enraizada em práticas sociais, discursos, controvérsias e convenções quenem sempre são rotuladas como "políticas", Lien ${ }^{2}$ entende que uma abordagem puramente institucional da alimentação como campo político não é mais capaz de capturar o vasto leque de conexões existentes entrea produção, a distribuição eo consumo de alimentos.

Neste artigo, nos propomos a destacar e re fletir sobre um novo aspecto político e politizador da alimentação. Isso não quer dizer, evidentemente, que a abordagem institucional não seja relevante nem que questões como a segurança alimentar enutricional não sejam menos importantes hoje do que sempre foram. A dimensão política da alimentação tem sido expandida em novas direções. Certos fatos, como os escândalos alimentares, as controvérsias científicas, a percepção e a publicização de riscos, as ideologias al imentares e os discursos e práticas de consumo consciente, colocam o tema da alimentação, cada vez mais, no centro dos debates políticos.
Daí surge a questão que pretendemos abordar: como a comida tem se transformado em um objeto político por excelência?

Como caso paradigmático para a politização da alimentação, tem sido apontado o escândalo da doença "encefalopatia bovina espongiforme" (Bovine Spongiform Encephalopathy - BSE), popularmentedesignada como "doença da vaca louca", ocorrido na Inglaterra em 1996 devido à reciclagem, sem controle, de carne, ossos, sangue e vísceras usados na fabricação de ração animal. Tal escândalo provocou reações em cadeia em todo o mundo e fez emergir uma forte consciência do risco, abalando a confiança pública nas instituições políticas ecientíficas e desencadeando um amplo debate sobre as consequências da produção de "comida barata" na esfera pública ingle$\mathrm{sa}^{2,3}$. Com a eclosão de outros escândal os alimentares - como a febre aftosa, a salmonela ea "gripe suína" - e o advento dos organismos geneticamente modificados, a partir da década de 90, a alimentação deixou de ser uma questão debatida apenas nos círculos restritos que definiam as políticas de segurança alimentar e nutricional para ganhar a grandemídia, o debate público ea esfera das decisões cotidianas de uma nova "agenda da mesa da cozinha" ${ }^{4}$, em especial no contexto europeu. Com isso, a alimentação começa a ser politizada tanto em suas formas de produção, distribuição e comercialização quanto em suas formas e locais de aquisição e preparo dos alimentos.

Barbosa ${ }^{5}$ assinala uma transição do ato de comer como a passagem de uma atividade corriqueira, prazerosa, privada e familiar para uma prática altamenteconsciente, regulada epolítica. Nestecontexto, indica as origens múltiplas da complexidade atual do campo da alimentação: o conhecimento científico sobrea nutrição humana ea medicina; 0 movimento ecológico, que pauta as implicações ambientais decorrentes do tipo dealimentação que as sociedades ocidentais contemporâneas adotam; os movimentos sociais em defesa de populações que vivem de métodos tradicionais de produção e se encontram ameaçadas pelas transformações ocorridas no campo; os movimentos em defesa dos animais; o processo de globalização; e o desenvolvimento das ciências sociais que vêm abordando os fenômenos de forma mais processual e relacional, por meio da análise de redes.

Assim, se o campo da alimentação é politizado através das políticas de produção agrícola e das políticas distributivas e nutricionais, cabe destacar que este processo de politização também se dá a partir da percepção dos riscos e da possibilidadedeuso político das escolhas decon- 
sumo. Neste sentido, a comida permanece um meio de reciprocidadeque, ao constituir relações significantes em diferentes níveis e de diferentes tipos, se transforma em um novo objeto político contemporâneo, já que muitas relações constituídas por e através da sua mediação são também relações de poder, devendo ser analisadas como tal ${ }^{2}$. Afinal, ações que contestam as relações de poder existentes podem tomar diferentes formas². Ao prestarmos atenção nas formas menos óbvias em que o campo da alimentação é politizado, buscamos contribuir para um meIhor entendimento tanto da política quanto da alimentação contemporânea.

Para uma abordagem política da alimentação, propomos, inicialmente, considerar o processo deambientalização e politização do consumo, ou seja, a percepção e o uso do consumo como uma forma de ação política, materializando e tornando públicos valores e comprometimentos ambientais esociais. Em seguida, descreveremos as transições do campo da alimentação como campo político ${ }^{2,3}$ e, como conclusão, apresentaremos uma necessária agenda de pesquisa capaz de captar os processos de politização da comida eas práticas deconsumo político no campo da alimentação.

\section{A politização e a ambientalização do consumo e da vida cotidiana}

A nova abordagem da alimentação como campo político pode ser compreendida dentro do quadro mais amplo de análise dos processos de ambientalização e politização da vida privada e cotidiana, traduzidos, em especial, na percepção eno uso do consumo como prática política, o que tem sido chamado de consumo político 6 .

Autores como Alexander ${ }^{7}$, Canclini ${ }^{8}$, Giddens ${ }^{9}$ e Beck ${ }^{10}$, entre outros, têm destacado mudanças nas formas de participação na esfera pública eno repertório de ação política das sociedades contemporâneas. N esse sentido, apontam para uma mudança das formas convencionais de participação política via instituições eação coletiva - como sindicatos, partidos políticos e movimentos sociais institucionalizados - para formas consideradas mais autônomas, menos hierárquicas e não institucionalizadas de participação, incluindo boicotes, compras responsáveis e petições on-line.

Ao considerar essas transformações nas formas de engajamento político, Canclini ${ }^{8}$ aponta uma redução da participação, do interesse e da confiança nas instituições políticas tradicionais e, ao mesmo tempo, uma reestruturação dos vínculos entre consumo e cidadania: a expansão das comuni cações e do consumo geram associações de consumidores elutas sociais, ainda marginais, mas melhor informados sobre as condições nacionais e internacionais.

Entendemos como consumo político a percepção e o uso das práticas e escolhas de consumo como uma forma de participação na esfera pública ${ }^{4,6,11-15}$. Trata-se de uma tentativa de dar concretude à adesão a valores em prol de melhorias sociais eambientais, materializando-os e tornando-os públicos. N este contexto, as ações eescoIhas mais triviaise cotidianas são percebidas como podendo influenciar rumos globais, ao mesmo tempo que setornam gl obalmente determinadas 9 . Desta forma, a vida privada torna-se o lócus de um novo tipo de ação política em que o aspecto politizador se constitui no fato de que o microcosmo das condutas pessoais se inter-relaciona com o macrocosmo dos problemas globais ${ }^{16}$.

Ao considerar essas transformações, os próprios conceitos deconsumo ede sociedadedeconsumo são repensados pelas ciências sociais, uma vez que categorias tradicional mente atribuídas a eles, como individualismo, insaciabilidade, superficialidade, anomia e alienação, são contrapostas à observação empírica de processos que associam as práticas de consumo a valores como solidariedade, responsabilidade, participação social e cidadania. Com isso, o consumo deixa deser apenas uma forma de reprodução das estruturas sociais reinantes ${ }^{17}$ para se tornar também, e cada vez mais, um instrumento e uma estratégia de ação política que incorpora valores como solidariedade e responsabilidade socioambiental.

A relação entre consumo e política pode ser observada ao prestarmos atenção nas novas ideologias, discursos emovimentos sociais que propõem, como solução para o enfrentamento de problemas sociais e ambientais, práticas de consumo responsável, consciente, ético ou sustentável. Tal fenômeno pode ser considerado sob o rótulo mais amplo de consumo político. Cabe destacar que pesquisas empíricas que analisam como e por que (ou por que não) os cidadãos individuais percebem suas responsabilidades e seu papel nas atividades cotidianas de consumo ${ }^{4,13-15,18,19}$ observam tensões, dilemas, incorporação, negociação enegação desses ideais. Afinal, o campo do consumo envolve uma encruziIhada devalores e práticas em disputa (consumption junction, na expressão de Stolle et al. $\left.{ }^{6}\right)$.

Dessa forma, o termo consumo político, ou politizado, tem sido utilizado para se referir ao 
uso do consumo como uma arena de tomada de decisão carregada de potenciais conflitos de valores e desejos, de capacidade política e de restrições socioeconômicas ${ }^{8,13,14}$. Essa visão difere das visões convencionais sobre o fenômeno do consumo, que tendem a vê-lo ou como mera compra e aquisição de bens e serviços no mercado com base em decisões sobre preço e qualidade ou como gastos desmedidos e supérfluos ${ }^{20}$. Interessa destacar que o enfoque do consumo político não aborda apenas consumidores engajados em movimentos sociais institucionalizados, mas enfatiza também, e principal mente, aquel es atores sociais "não organizados" e difusamente politizados que se situam entre 0 anonimato e a vontade de exercer um papel político, entre as preocupações cotidianas da esfera privada e a vontade departicipar deuma esfera pública mais ampla $14,15,21$.

No estudo do processo de politização do consumo, $\mathrm{H}$ alkier e $\mathrm{H}$ olm ${ }^{15}$ e Stolle et al. ${ }^{6}$ enfatizam o engajamento dos consumidores em dois conjuntos de práticas de consumo político: boicotes e buycotts. Tais práticas se relacionam, no primeiro caso, à negação do consumo de produtos e serviços por considerações sociais e/ou ambientais e, no segundo, à opção intencional por produtos e serviços percebidos como social e/ou ambientalmente amigos. Cabe citar, ainda, um terceiro conjunto de práticas: as de uso racional debens e serviços na esfera doméstica e cotidiana (como água, energia e transportes) e separação de resíduos para reciclagem ${ }^{19,22}$.

Essas práticas que ocupam novos espaços fora do campo político tradicional podem ser analisadas através de propostas analíticas desenvolvidas por autores como Jeffrey Alexander ${ }^{7}$, Anthony Giddens ${ }^{9,23}$ e ÜIrich Beck ${ }^{10,16}$, que não desmerecem a vida privada como espaço de luta pela emancipação ${ }^{14,22}$. Assim, o consumo político pode ser compreendido como consequência de fatores que têm transformado práticas locais e experiências sociais nas últimas décadas, como a globalização, a destradicionalização e a reflexividade social.

Giddens ${ }^{9}$ ressalta que, em uma ordem social pós-tradicional, perderíamos as referências dadas pelas tradições, tendo que decidir e escolher, por nós mesmos, na condição de indivíduos e humanidade col etiva, o queéa natureza e como deve mos organizar nossas vidas em relação a ela. Com isso, os indivíduos precisam se acostumar a refletir ea filtrar as informações sobre todos os aspectos rotineiros da vida cotidiana, tomando decisões com base nessas reflexões e conhecimentos.
Assim, o relativo crescimento da liberdadede escolha dos consumidores é conectado a uma busca pela emancipação, identidade pessoal e autonomia na esfera privada, apontando para novas formas de ação política. Com base nesses fenômenos, novas preocupações se juntariam às políticas emancipatórias tradicionais, dando origem às políticas de vida, que apontam para um padrão de engajamento relacionado às lutas sobre como queremos viver, como indivíduos e como humanidade, num mundo que era determinado pela tradição e pela natureza e que agora se encontra, cada vez mais, submetido às decisões humanas.

Beck ${ }^{10,16}$ enfatiza que, em contraposição à descrença nas instituições políticas tradicionais, ocorreum renascimento não institucional do político, em que distintas áreas sociais passam a se constituir como uma nova cultura política. Assim, sena modernidadeclássica o conceito de política significava deixar a esfera privada para se dedicar à pública, com a atual invasão do político na esfera privada as experiências que eram consideradas declínio ou morteda política podem ser pensadas como reposicionamento do político. Na modernização reflexiva, esse autor observa uma ampliação do conceito de política na medida em que a redução da participação pública nas esferas tradicionais refleteum processo detransição em que as velhas políticas dão lugar às novas políticas, concentradas na vida privada.

Esse renascimento não institucional do político pode ser explicado por meio do conceito de subpolítica, uma política à margem e além das instituições políticas dos Estados- $N$ ação; uma política direta que envolve a partici pação individual nas decisões. Para Beck ${ }^{16}$, na sociedade de risco global, a privacidade - como a menor unidade concebível do político - contém dentro de si a sociedade mundial. Esta nova qualidade do político se fortalece justamente com a expansão da preocupação ecológica e com os riscos associados ao desenvolvimento tecnológico.

A teoria neomoderna proposta por Alexander ${ }^{7}$ ajuda a compreender a transição no padrão de engajamento político das sociedades contemporâneas, das ações radicais-col etivistas, predominantes no período de antimodernização dos anos 1960 e 1970, para as ações romântico-individualistas, típicas do período de neomodernização, a partir dos anos 1990. Essas formas emergentes de ação política seriam mais realistas e pragmáticas por enfatizarem a ação de indivíduos reaisenão desujeitos históricos coletivos, como as categorias "nação", "classe social" ou "movi- 
mentos sociais". As narrativas e formas de ação política atuais - emancipatórias, individualistas e românticas, mas igualmente heroicas - parecem conectadas a uma ampla variedade de ações na esfera do mercado.

Assim, e por meio do que denomina de "reconvergência neomoderna", Alexander ${ }^{7}$ enfatiza o (res) surgimento de uma narrativa emancipatória do mercado em que este passa a ser visto como uma relação social e interativa, e não mais apenas um mercado capitalista explorador, na medida em que a narrativa heroica reaparece por meio de movimentos sociais com uma ampla variedade de motivações para construir novos direitos e formas de ação.

Todos esses processos podem, ainda, contribuir para aumentar o sentimento de pertencimento na sociedade, uma vez que os consumidores podem perceber o significado de suas próprias ações em relação aos seus efeitos no meio ambiente e em outros grupos sociais, conectando as esferas local e global ${ }^{23}$. I sso poderia produzir sentimentos de cidadania mais fortes, uma vez que os consumidores podem passar a ver suas próprias práticas como pertencendo a uma comunidade política mais ampla ${ }^{4,8}$.

0 ato de selecionar e adquirir mercadorias, portanto, não pode ser compreendido como um ato individual eindividualizante. Ao contrário, 0 consumo se relaciona a duas formas de alteridade $^{24}$ : uma relação entre quem compra e para quem se compra, em geral a família, e uma relação cosmológica que transcende qualquer utilidade imediata, pois assume a forma não de sujeito ou objeto, mas dos valores aos quais as pessoas desejariam se dedicar. A seleção de mercadorias está, portanto, relacionada às relações sociais e aos valores mais importantes para a pessoa responsável por esta tarefa. Assim, a ideia de responsabilidade pode ser ampliada para outros grupos sociais e para uma ideia abstrata de "mundo", "natureza" e "planeta"25.

0 aspecto político e politizador da comida: transformações no campo da alimentação

Os anos 1990 representaram uma virada histórica na configuração da alimentação como campo político. Com isso, cada garfada passa a articular experiências locais, particulares esubjetivas do ato de comer a eventos que ocorrem no cenário global. Este novo papel da alimentação nas sociedades contemporâneas se relaciona à maior consciência das questões envolvidas no consu- mo alimentar, às responsabilidades derivadas desta consciência, às implicações da globalização e ao teor político e ideológico destas questões ${ }^{26}$. Assim, e para além de práticas relacionadas com a satisfação de necessidades nutricionais, modeladas pela cultura e imprescindíveis para a vida e a sobrevivência humanas ${ }^{1}$, o "comer" torna-se também um ato político eideológico.

Lien $^{2}$ aponta a governamentalidade, o problema dos riscos e a dimensão de natureza da comida como algumas das principais facetas politizadoras presentes nos estudos contemporâneos sobre alimentação.

$\mathrm{Na}$ perspectiva da alimentação como governamentalidade, a comida surge como mediadora das relações entre o Estado, as corporações e os indivíduos e, ainda, entre a nação e seu corpo humano, envolvendo, assim, a socialização dos membros da família como bons pais, boas crianças e bons cidadãos, bem como a construção de sujeitos éticos e de probidademoral. Em relação à crescente percepção dos riscos na alimentação, destacam-se estudos sobre reflexividade institucional, incerteza e confiança. Se o que é considerado perigoso na comida escapa aos sentidos, a confiança em relação à comida passa a ser abstrata, envolvendo "políticas discursivas" e formas de construir e organizar o debate público, publicizando ou silenciando sobre os riscos. Finalmente, a dimensão da comida como natureza envolve uma imagem idealizada desta última, oposta à cultura e tecnologia, que captura nossa imaginação do que é bom, saudável, verdadeiro eautêntico.

Para além dessas facetas, Lien ${ }^{2}$ aponta a capacidade de efetuar conexões como a característica que confere especificidade política às práticas alimentares nas sociedades contemporâneas. Neste sentido, as conexões marcam politicamente 0 campo da alimentação, indicando possibilidades de dissolver muitas distinções preconcebi das entre natureza e cultura, produção e consumo, moral e mercado, família e sociedade, individual e coletivo, corpo e mente'2. Desta forma, o campo da alimentação se torna político na medida em que muitas relações de poder se constituem nele e por meio dele. A alimentação passa a configurar um campo de disputas específicas que conectam o corpo individual a comunidades abstratas, ao meio ambiente, a inovações tecnocientíficas ea conceitos morais, evidenciando dilemas acerca dos riscos e do controle que caracterizam a produção de alimentos nas sociedades contemporâneas.

Lien $^{2}$ compreende, assim, um movimento duplo de mudança, que envolve um desencaixe 
local eum reencaixeglobal, com um impacto cada vez mai or de eventos locais em contextos distantes de uma ordem globalizada. Assim, certos indivíduos passaram a se autoatribuir responsabilidades ${ }^{27}$ ante consequências distantes, complexas e abstratas de suas escolhas e hábitos, inse rindo a vida cotidiana no campo político. Por sua vez, os consumidores gl obais ficam vulneráveis a práticas, regulações e rotinas originadas em regiões distantes e desconhecidas. Com isso, as negligências, fraudes e adulterações do complexo agroalimentar industrial hegemônico passam a representar riscos para todos os consumidores de alimentos.

Importante destacar quenão ésomenteo fato de a comida se tornar gl obalizada que faz da alimentação um campo político, nem mesmo a ampliação dos interesses, relações e instrumentos regulatórios envolvidos na trajetória do alimento da produção ao consumo. Um potencial maior deinteresses divergentes e conflitantes torna as relações políticas do alimento e da comida mais significativas, pois cada alimento passa a ser reconhecido como um produto que possui uma história eimplicações mais complexas e profundas do que se pensara até então.

0 espaço entre "o que sabemos" e"o que poderíamos saber" confere à segurança e à transparência um caráter fundamental nas análises sobre a alimentação contemporânea². Por isso, uma abordagem política do campo da alimentação é, ao mesmo tempo, silenciosa e expositiva na medida em que envolve o poder de controlar o que será declarado e a definição do foco de debate público, assim como o que deixará de ser declarado. As relações abstratas entre produtores e consumidores, o enfraquecimento da autoridade especialista e a divulgação frequente dos escândalos alimentares na mídia são aspectos que fazem com que os consumidores sintam mais fortemente a impossibilidade de ser e estar bem informados ${ }^{2}$.

Desta forma, a politização do campo da alimentação pareceir além de um processo seletivo de escolha por um alimento específico dentro de uma miríade de possibilidades. A questão sobre qual item deve ser politizado por si só se tornou um instrumento político em razão dos dilemas e ambiguidades envolvidos nas escolhas cotidianas dos consumidores.

$\mathrm{Nerlich}^{3}$ entendeque a escolha dos riscos que mais nos preocupam está associada a formas sociais específicas, pois são simultâneas às escoIhas dos estilos de vida. 0 risco não é construído apenas de uma forma científica, social e cultural, mas envolve uma questão individual cada vez mais importante, bem como, ultimamente, uma questão de moralidade, materializada nas escoIhas dos consumidores. Com isso, as reflexões cotidianas passaram a incluir aspectos como a globalização, a responsabilidade individual, o julgamento científico e as pressões socioeconômicas. Os riscos, que à primeira vista pareciam somente uma tragédia humana e ambiental, passaram a abrir janelas de oportunidades políticas no campo da alimentação.

$\mathrm{Na}$ era da alimentação globalizada, as fronteiras entre os contextos locais e global apresentam-se cada vez mais diluídas. Desta maneira, a alimentação constitui um fenômeno político úni$\mathrm{co}$, pois o alimento, mais do que qualquer outro produto, é profundamente absorvido por complexas relações. E isso se dá, segundo Lien², em três sentidos. Primeiramente, em relação às implicações biológicas da alimentação, ou seja, a necessidade humana fisiológica de se alimentar diariamente. Historicamente, os sistemas agroalimentares foram desenvolvidos para assegurar, de diversas formas, o suprimento estável de alimentos: domesticação, exploração, reciprocidade e comércio. Esta relativa estabilidade tornou os seres humanos vulneráveis, fracos e fáceis de controlar, o que torna o campo da alimentação parte de estruturas de subordinação, governança e dominação.

Em segundo lugar, a alimentação caracteriza uma rotina cotidiana, um meio conveniente de expressar distinções sociais e cerimoniais que naturaliza relações comunitárias ou hierárquicas. O significado simbólico da comida em um contexto social pode ser visto como sedimentação de estruturas históricas de poder e desigualdade que operam ao longo de geraç̧ões ${ }^{2,17}$. Desta forma, a alimentação se torna uma força estrutural e estruturante.

Em terceiro lugar, o campo da alimentação passa a ser entendido como "ciência nutricional", uma vez que a nutrição se tornou um dos mais significativos campos da medicina preventiva e um agente estruturante das escolhas alimentares contemporâneas. A nutrição contraria, ao mesmo tempo, os interesses agrícolas, da indústria alimentar, da comida nacional e das políticas nutricionais ${ }^{2}$. Desta forma, as conexões entre 0 alimento e o corpo podem evidenciar conflitos entre diferentes interesses: políticos, de negócios edaciência.

Esta abordagem política do campo da alimentação passa ao largo das instituições estatais formais, especialmentepela crise delegitimidadeque 
as atinge, em geral, bem como pela desregulamentação e liberalização que afetam o campo da alimentação, em particular. N este sentido, a contestação das relações de poder existentes pode assumir diversas formas, muitas vezes pel os caminhos menos óbvios, como os da vida cotidiana. Lien ${ }^{2}$ destaca quatro conexões nas relações de poder do campo da alimentação: (1) entre os sentidos e as experiências, uma vez que a alimentação evoca e estimula a memória; (2) o conceito de governamentalidade, definido por Michel Foucault; (3) a reflexividadeinstitucional ${ }^{23}$, sociedadederisco ${ }^{10}$ ou termos como "dúvida radical", "incerteza" e "falta de confiança", que se referem ao conjunto de dilemas sentidos contemporaneamente; e, finalmente, (4) a comida como natureza.

Por fim, é necessário atentar para as políticas da natureza englobadas discursivamentepelo termo ambientalismo, uma vez que não há uma natureza única e singular, mas uma diversidade de naturezas contestadas e constituídas através de vários processos políticos, sociais e culturais. Assim, quando um alimento é visto como mais ou menos "natural", produzido de um modo mais ou menos "sustentável" ou harmoniosamente adaptado a certas noções de natureza, o que se tem, de fato, é a inserção dos debates em um campo em que o que prevalece é a dúvida.

Com base em uma pesquisa com consumidores de alimentos orgânicos na Dinamarca, $\mathrm{H}$ alkier ${ }^{18}$ compreen de que os riscos associados à alimentação se inserem em teias sociais e culturais mais complexas e diversificadas do que supõe a racionalidade instrumental dos debates públicos, em especial por parte das instituições políticas. Em sua análise, a autora demarca as diferentes formas deenxergar os riscos, colocando, de um lado, pesquisadores, políticos e administradores que enfatizam questões como qualidade, segurança e ética alimentar e, de outro, 0 público em geral, que se volta mais para as normas sociais práticas que governam o consumo de alimentos.

Assim, no momento em que os consumidores se dão conta dos riscos associados ao consumo dealimentos, ingressam na arena política que, no campo da alimentação, secaracteriza pelo crescentenúmero deescândalos alimentares e conflitos de controleeregulação, bem como pelo grande número de discursos conflituosos. Desta forma, alguns consumidores constroem suas práticas cotidianas de alimentação como uma ação política individualizada, local e orientada para uma solução concreta em relação aos riscos que percebem ${ }^{18}$. Quando os consumidores negociam as normas sociais das práticas de consumo alimentar, eles estão negociando o controle de suas próprias práticas de consumo.

\section{Conclusão:}

uma necessária agen da de pesquisa

Conforme exposto, os debates sobre a alimentação como campo político deixaram a exclusividade da esfera política institucional para atingir também as atividades privadas, cotidianas e rotineiras de consumo alimentar.

As reflexões aqui apresentadas nos levam a um esforço de apontar uma necessária agenda de pesquisa capaz de captar esses novos processos de politização da alimentação, bem como as práticas de consumo político nesse campo.

Tal agenda de pesquisa tem se mostrado profícua entre pesquisadores estrangeiros, entre os quais se observa vasta produção acadêmica abordando temas como a governamental idade, o problema dos riscos, a dimensão de natureza da comida e o consumo político no contexto alimentar, bem como as conexões nas relações de poder presentes no campo da alimentação, conforme apresentado neste artigo.

No entanto, nos parece ainda haver uma carência de reflexões e investigações empíricas sobre consumo político no Brasil, o que contrasta com a observação do crescimento, em nosso país, de experiências como redes de produtores econsumidores, associações de compras coletivas, boicotes, buycotts e, ainda, a adoção do consumo político por diversos movimentos sociais como estratégia para alcançar seus objetivos como, por exemplo, os movimentos de economia solidária e comércio justo.

Acreditamos que as reflexões sobre a al imentação como campo político devem incluir investigações relacionadas a questões como a politização do consumo alimentar como tendência nas sociedades contemporâneas, as especificidades desse fenômeno no contexto brasileiro, os limites e possibilidades desse tipo de ativismo, a capacidade de o consumo político alterar agendas epautar políticas públicas e empresariais, a conjugação (ou não) do consumo político com a participação via formas institucionalizadas e coletivas e as opções metodológicas capazes de captar os processos de politização do consumo alimentar. 


\section{Colaboradores}

F Portilho, M Castañeda e IRR Castro participaram igualmente na concepção e redação final deste artigo .

\section{Referências}

1. Canesqui AM, Garcia RWD. Introdução. In: Canesqui AM, Garcia RWD, organizadoras. Antropologia e nutrição: um diálogo possível. Rio de Janeiro: Editora Fiocruz; 2005.

2. Lien ME. The politics of food: an introduction. In: Lien $M E$, N erlich $B$, organizadores. The politics of food. Oxford, New York: Berg; 2004. p. 1-17.

3. Nerlich B. Risk, blame and culture: foot and mouth disease and the debate about cheap food. In: Lien ME, Nerlich B. The politics of food. Oxford, New York: Berg; 2004. p. 39-57.

4. Halkier B. Consequences of the politicization of consumption: the example of environmentally friendly consumption practices. Journal of Environmental Policy and Planning 1999; 1(1):25-41.

5. Barbosa L. Tendências da alimentação contemporânea. In: Pinto ML, Pacheco JK, organizadores. Juventude, consumo e educação 2. Porto Alegre: ESPM ; 2009. p. 15-64.

6. Stolle $D, H$ ooghe $M, M$ icheletti $M$. Politics in the supermarket: political consumerism as a form of political participation. International Political Science Review 2005; 26(3):245-269.

7. Alexander J. Modern, ante, post, and neo: how intellectuals have coded, narreted, and explained the "crisis of our times". In: Alexander, J. Fin-desiècle social theory: relativism, reduction, and the problem of reason. Londres: Verso; 1995. p. 7-64.

8. Canclini NG. Consumidores y ciudadanos: conflictos multiculturales de la globalización. M éxico: Editorial Grijalbo; 1995.

9. Giddens A. Para além da esquerda e da direita: 0 futuro da política radical. São Paulo: Unesp, 1996.

10. Beck U. La sociedad del risco global. Madrid: Sieglo XXI de Espana Editores; 2002.

11. Gabriel Y, Lang T. The unmanageable consumer: contemporary consumption and its fragmentation. London: Sage Publications; 1995.

12. Goodman D, Dupuis E. Knowing food and growing food: beyond the production-consumption debate in the sociology of agriculture. Sociologia Ruralis 2002; 42:5-22.

13. Micheletti M. Political virtue and shopping: individuals, consumerism, and collective action. New York: Palgrave; 2003.

14. Portilho F. Sustentabilidade ambiental, consumo e cidadania. São Paulo: Cortez; 2005.

15. Halkier B, Holm L. Food consumption and political agency: on concerns and practices among Danish consumers. International Journal of Consumer Studies 2008; 32(6):667-674.
16. Beck U. A reinvenção da política: rumo a uma teoria da modernização reflexiva. In: Giddens A, Lash S. M odernização reflexiva: política, tradição e estética na ordem social moderna. São Paulo: Unesp; 1997. p. 11-71.

17. Bourdieu P. A distinção: crítica social do julgamento. São Paulo, Porto Alegre: Edusp, Zouk; 2008.

18. Halkier B. Handling food-related risks: political agency and governamentality. In: Lien ME, Nerlich B. The politics of food. Oxford, New York: Berg; 2004. p. 21-38.

19. Castañeda de Araújo M. Ambientalização e politização do consumo e da vida cotidiana: uma etnografia das práticas de compra de alimentos orgânicos em N ova Friburgo/RJ [dissertação]. Rio de Janeiro: U niversidade Federal Rural do Rio de Janeiro; 2010.

20. Barbosa L, Campbell C. 0 estudo do consumo nas ciências sociais contemporâneas. In: Barbosa L, Campbell $\mathrm{C}$, organizadores. Cultura, consumo e identidade. Rio de Janeiro: Editora FGV; 2006.

21. Paavola J. Economics, ethics and green consumerism. In: Cohen M, Murphy J, organizadores. Exploring sustainable consumption: environmental policy and the social sciences. Oxford: Elsevier Science; 2001. p. 79-96.

22. Portilho F, Castañeda M. Consumo e política: neomodernismo e reflexividade social. Anais do XVI Congresso Brasileiro de Sociologia. Rio de Janeiro; 2009.

23. Giddens $A$. As conseqüências da modernidade. São Paulo: Unesp; 1991.

24. M iller D. Teoria das compras: o que orienta as escoIhas dos consumidores. São Paulo: N obel; 2002.

25. Portilho F. Consumidores de alimentos orgânicos: discursos, práticas e auto-atribuição de responsabilidade socioambiental. Anais da XXVI Reunião Brasileira de Antropologia. Porto Seguro (BA); 2008.

26. Barbosa L. Comida e sociabilidade no prato do brasileiro. In: Barbosa L, Veloso L, Portilho F, organizadores. Consumo: cosmologias e sociabilidades. Rio de Janeiro: Edur/M auad; 2009. p. 39-59.

27. Eden SE. Individual environmental responsibility and its role in public environmentalism. Environmental and Planning 1993; 25:1743-1758.

Artigo apresentado em 10/02/2010

Aprovado em 20/05/2010

Versão final apresentada em 12/07/2010 